\title{
Ultrafast Dynamics of Sb-Corroles: A Combined Vis-Pump Supercontinuum Probe and Broadband Fluorescence Up-Conversion Study
}

\author{
Clark Zahn ${ }^{1}$, Till Stensitzki ${ }^{1}$ (D), Mario Gerecke ${ }^{2}$, Alexander Berg ${ }^{3}$, Atif Mahammed ${ }^{4}$, \\ Zeev Gross ${ }^{4}$ and Karsten Heyne ${ }^{1, *}$ \\ 1 Department of Physics, Free University Berlin, Arnimallee 14, D-14195 Berlin, Germany; \\ clark.zahn@fu-berlin.de (C.Z.); tillsten@zedat.fu-berlin.de (T.S.) \\ 2 Department of Chemistry, Humboldt-Universität zu Berlin, Brook-Taylor-Str. 2, D-12489 Berlin, Germany; \\ Mario.gerecke@chemie.hu-berlin.de \\ 3 Institute of Chemistry, The Hebrew University of Jerusalem, Jerusalem 91904, Israel; \\ alexander.berg@mail.huji.ac.il \\ 4 Schulich Faculty of Chemistry, Technion-Israel Institute of Technology, Haifa 3200008, Israel; \\ chatif@technion.ac.il (A.M.); chr10zg@technion.ac.il (Z.G.) \\ * Correspondence: karsten.heyne@fu-berlin.de; Tel.: +49-30-8385-6107
}

Received: 31 May 2017; Accepted: 10 July 2017; Published: 13 July 2017

\begin{abstract}
Corroles are a developing class of tetrapyrrole-based molecules with significant chemical potential and relatively unexplored photophysical properties. We combined femtosecond broadband fluorescence up-conversion and fs broadband Vis-pump Vis-probe spectroscopy to comprehensively characterize the photoreaction of 5,10,15-tris-pentafluorophenyl-corrolato-antimony(V)-trans-difluoride (Sb-tpfc- $\mathrm{F}_{2}$ ). Upon fs Soret band excitation at $\sim 400 \mathrm{~nm}$, the energy relaxed almost completely to $\mathrm{Q}$ band electronic excited states with a time constant of $500 \pm 100 \mathrm{fs}$; this is evident from the decay of Soret band fluorescence at around $430 \mathrm{~nm}$ and the rise time of $Q$ band fluorescence, as well as from $Q$ band stimulated emission signals at 600 and $650 \mathrm{~nm}$ with the same time constant. Relaxation processes on a time scale of 10 and 20 ps were observed in the fluorescence and absorption signals. Triplet formation showed a time constant of $400 \mathrm{ps}$, with an intersystem crossing yield from the $\mathrm{Q}$ band to the triplet manifold of between $95 \%$ and $99 \%$. This efficient triplet formation is due to the spin-orbit coupling of the antimony ion.
\end{abstract}

Keywords: photoreaction; triplet formation; femtosecond spectroscopy; fluorescence up-conversion; corrole dynamics; tetrapyrrole; ultrafast relaxation; intersystem crossing

\section{Introduction}

Corroles are a developing class of tetrapyrrole-based photosensitizers with relatively unexplored photophysical properties [1-4]. The simple and efficient procedure of corrole synthesis, combined with the pre-tuning of physical and chemical characteristics by varying the peripheral substituents [5-8], central metal $[6,9,10]$, and axial ligands [11,12], has revived substantial interest in employing these contracted porphyrinoids in various fields. A wide range of applications has been reported: corroles are used in dye-sensitized solar cells $[9,13]$, as photosensitizers in photodynamic therapy and photodynamic detection [14-17], for the photodynamic inactivation of mold fungi and green algae [18,19], for regular and sophisticated optical imaging [20,21], for the formation of singlet oxygen for catalysis [22-24] and for corrole-based electron and energy transfer systems [25-27]. Since many of the processes involving corroles proceed via transient paramagnetic states, revealing the mechanisms and parameters of these states as well as identifying their reaction pathways is central 
to the optimized application of corroles [8,28-39]. However, there are only a few in-depth reports tracking the photoreaction of corroles [35,39-46]. A combined study on the ultrafast electronic and vibrational dynamics of a brominated corrole system demonstrated intersystem crossing to the triplet manifold with a time constant of $100 \mathrm{ps}$ and a quantum yield of close to one [39]. Whether efficient intersystem crossing can only be achieved by heavy atom insertion at the macrocycle ring or can also be realized by varying the peripheral substituents and/or axial ligands, causing macrocycle distortion and thus leading to changes in the electronic structure of the complex, is not fully understood. Moreover, it is also unclear if the absorption spectra of the triplet and singlet excited states are similar for most corroles or if the spectra are sensitive to metal ions and ligands. It has been reported that excitation of the Soret band at around $400 \mathrm{~nm}$ leads to energy relaxation into $Q$ band states between $500 \mathrm{~nm}$ and $700 \mathrm{~nm}$ within a picosecond, accompanied by the rise of $Q$ band fluorescence [37]. Whether an intersystem crossing takes place during Soret band to $Q$ band transitions is unknown.

Here we report a study into the ultrafast electronic dynamics of a 5,10,15-tris-pentafluorophenylcorrolato trianion (tpfc) chelating an antimony metal ion. The antimony corrole is further stabilized by two axial fluorides forming a Sb-tpfc- $\mathrm{F}_{2}$ complex (see inset of Figure 1). The ultrafast dynamics were investigated by a combination of two complementary time-resolved spectroscopy methods: broadband fluorescence up-conversion and broadband absorption spectroscopy.

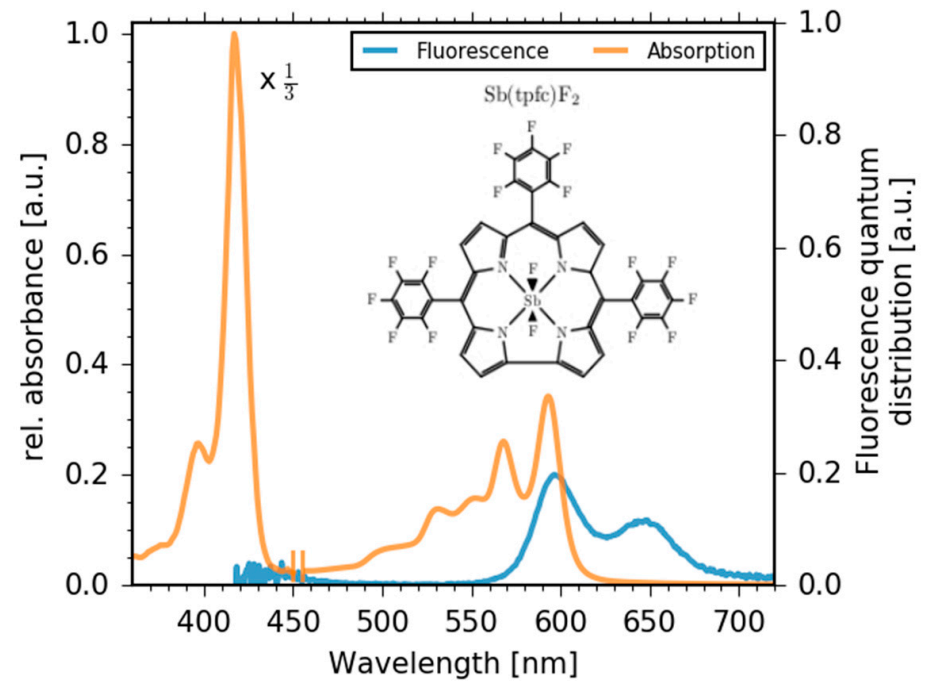

Figure 1. Steady-state absorption (orange line) and stationary fluorescence (blue line) of 5,10,15-trispentafluorophenyl-corrolato-antimony(V)-trans-difluoride (Sb-tpfc- $\left.\mathrm{F}_{2}\right)$. Inset: Schematic of Sb-tpfc- $\mathrm{F}_{2}$. Note, the short wavelength part of the absorption spectrum up to $450 \mathrm{~nm}$ is scaled-down by a factor of 3 .

\section{Results}

Steady-state absorption (orange line) and stationary fluorescence spectra (blue line) are displayed in Figure 1. The Soret band peaks at $410 \mathrm{~nm}$, while two $Q$ band peaks are clearly visible at $565 \mathrm{~nm}$ and $590 \mathrm{~nm}$. The fluorescence spectrum (blue line) exhibits two prominent peaks at $596 \mathrm{~nm}$ and $650 \mathrm{~nm}$. Moreover, a weak fluorescence contribution is indicated around $450 \mathrm{~nm}$.

\subsection{Transient Fluorescence Measurements}

Dynamics of electronic transitions show absorption and emission or fluorescence signals. A clean detection of fluorescence signals is only possible by way of time-resolved fluorescence measurements. Here, we applied Vis-pump/broadband up-conversion fluorescence spectroscopy with a system response of $100 \mathrm{fs}$ to track fluorescence dynamics in a spectral range from 417 to $720 \mathrm{~nm}(14,000$ to $24,000 \mathrm{~cm}^{-1}$ ) over time. In Figure 2, the time-resolved fluorescence map is plotted for delay times up to $4 \mathrm{ps}$ after Soret band excitation at $400 \mathrm{~nm}\left(25,000 \mathrm{~cm}^{-1}\right)$. 


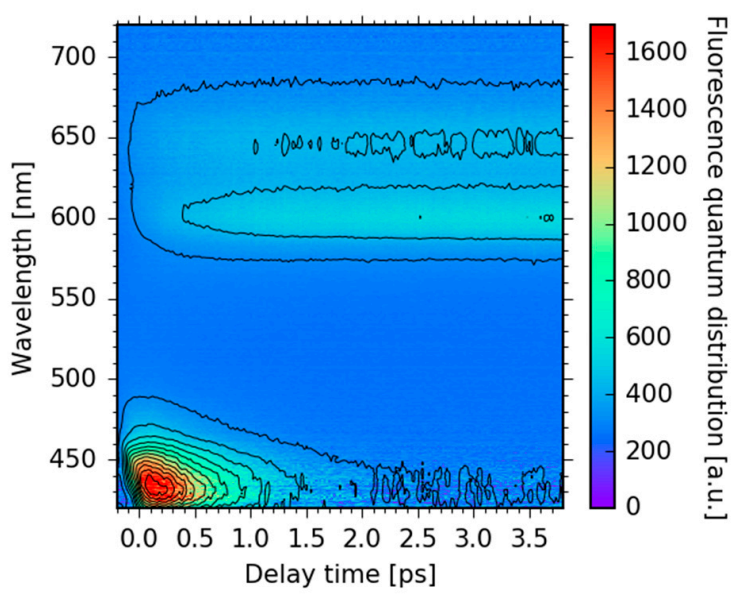

Figure 2. Fluorescence map of Sb-tpfc- $\mathrm{F}_{2}$ upon excitation at $400 \mathrm{~nm}$. The fluorescence wavelength in $\mathrm{nm}$ is plotted as a function of delay time in ps. Fluorescence quantum distributions are color coded.

For early delay times, of up to $500 \mathrm{fs}$, significant fluorescence is detected only at around $430 \mathrm{~nm}$ $\left(23,000 \mathrm{~cm}^{-1}\right)$, indicating direct fluorescence from the Soret band electronic states, violating Kasha's rule. The transient of the Soret band fluorescence is plotted in Figure $3 \mathrm{~b}$ and shows a mono-exponential decay with a time constant of $0.5 \pm 0.1 \mathrm{ps}$. As depicted in Figure 2, the decay of the Soret band fluorescence is accompanied by the rise of the fluorescence in the $Q$ band at around $600 \mathrm{~nm}\left(16,600 \mathrm{~cm}^{-1}\right)$. Closer inspection of the $Q$ band fluorescence shows a rise of the fluorescence in the spectral range from 570 to $700 \mathrm{~nm}\left(15,000\right.$ to $17,500 \mathrm{~cm}^{-1}$, see Figure 3a) with a time constant of $0.5 \pm 0.1$ ps (see Figure $3 b$ ). A similar decay of the Soret band fluorescence accompanied by a rise of the $\mathrm{Q}$ band fluorescence on a sub-picosecond time scale was previously observed in the case of aluminum corroles with two pyridine ligands (Al-tpfc-py 2 ) in a study of selected fluorescence wavelengths [37]. Here, we can also track subtle changes in the fluorescence spectrum, pointing to additional dynamics as depicted in Figure 3a. On a picosecond time scale, the Soret band fluorescence vanishes and only Q band fluorescence is observed.
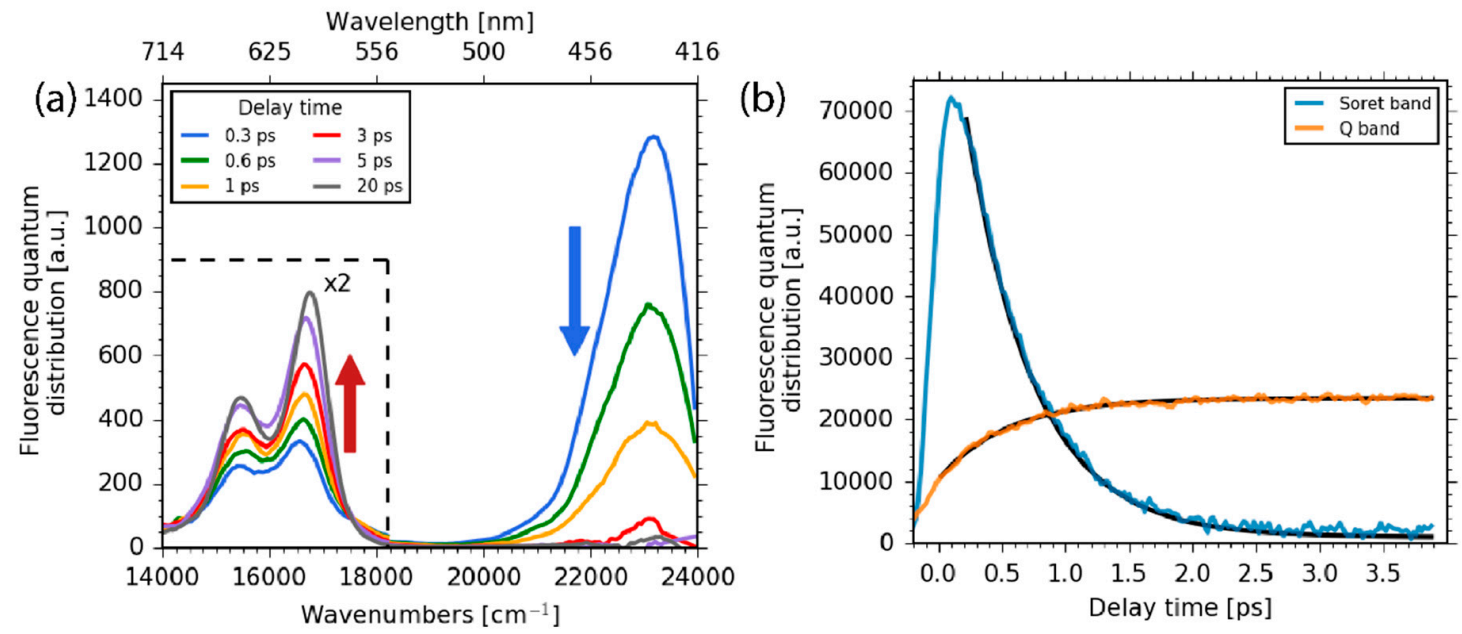

Figure 3. (a) Fluorescence spectra for selected delay times. The decay of the Soret band (blue arrow) and the subsequent rise of $Q$ band fluorescence (red arrow) is clearly visible. For delay times of 5-20 ps, the two $Q$ band fluorescence peaks shift to higher frequencies; (b) The integrated fluorescence transient of the Soret band region from 417 to $500 \mathrm{~nm}$ (blue line) and mono-exponential simulation with a time constant of $0.5 \pm 0.1 \mathrm{ps}$; integrated fluorescence transients of the $\mathrm{Q}$ band region (orange line) with a mono-exponential rise time constant of $0.5 \pm 0.1 \mathrm{ps}$. 
The fluorescence decay was measured up to delay times of $500 \mathrm{ps}$ in the entire spectral range from 14,000 to $24,000 \mathrm{~cm}^{-1}$. The spectral decay of $\mathrm{Q}$ band fluorescence is displayed in Figure $4 \mathrm{a}$ and the fluorescence decay is presented in Figure $4 \mathrm{~b}$, simulated with a time constant of $450 \pm 40$ ps. The loss of fluorescence on this time scale could be explained by triplet formation, which would be consistent with previously-observed phenomena by time-resolved electron paramagnetic resonance (EPR) studies [47]. Yet, a definite assignment is not possible and the exact photophysics remain uncertain.
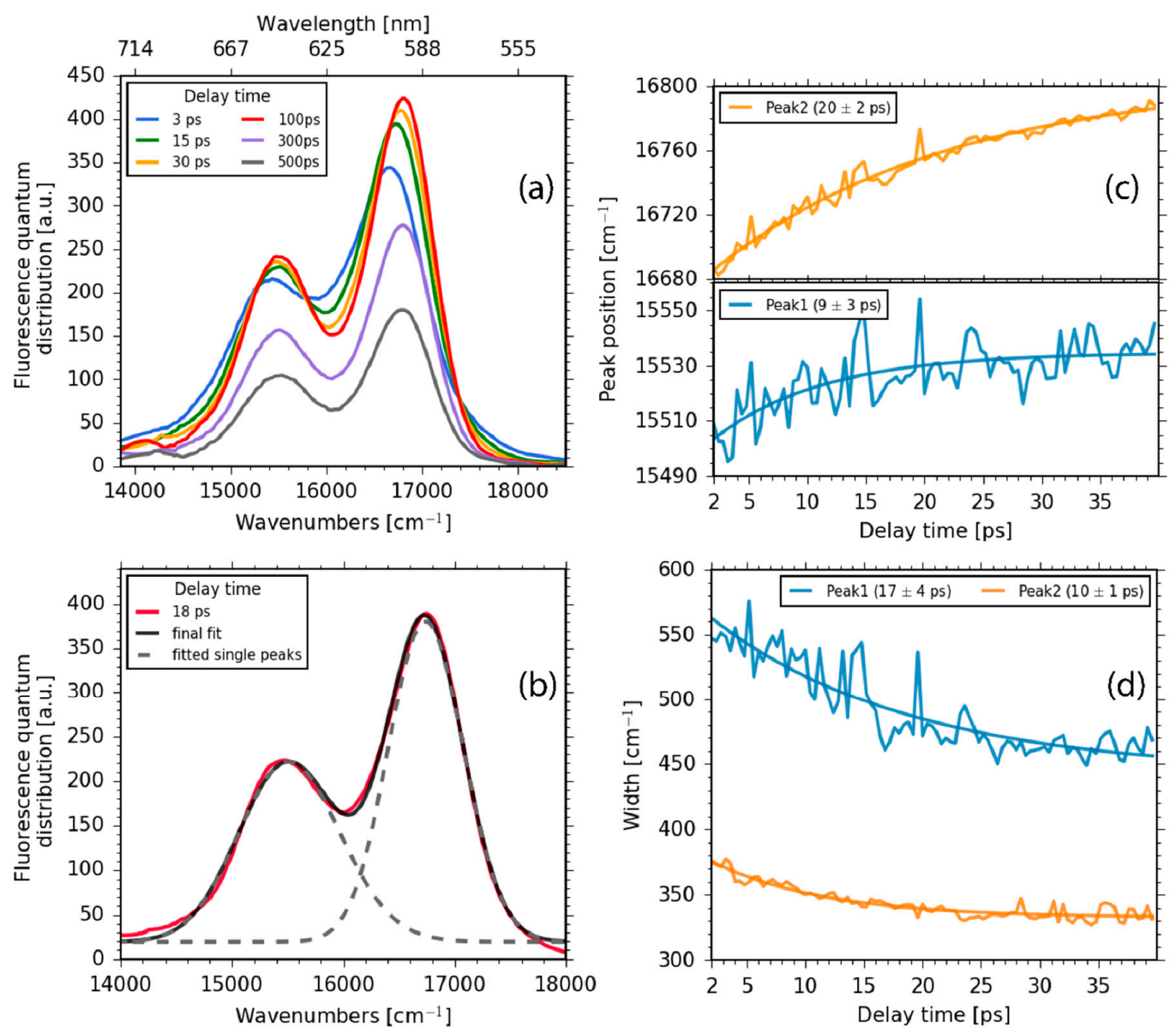

Figure 4. (a) Fluorescence spectra for selected delay times. The spectral blue-shift and narrowing of the bands is clearly visible for early delay times, while the overall decay is visible for later delay times; (b) Log-normal fit of the $\mathrm{Q}$ band fluorescence (dashed lines). lognormal $(v)=(2 \pi)^{-0.5}(\sigma v)^{-1} \exp \{[\ln (v)$ $\left.-\mu]^{2} /\left[2 \sigma^{2}\right]\right\}+c$, with the standard deviation $\sigma$ and the mean value $\mu$. The fit was used to determine the peak positions and peak widths (full width at half maximum (FWHM)); (c) Transient spectral blue-shift of the peak positions; (d) Narrowing of the fluorescence peaks as a function of time.

A closer inspection of the subtle changes of the two $\mathrm{Q}$ band fluorescence peaks at around $15,500 \mathrm{~cm}^{-1}$ and $16,700 \mathrm{~cm}^{-1}$ exhibits a spectral shift to higher energies. For detailed analysis, the spectrum was fitted with two log-normal distributions (see Figure $4 \mathrm{~b}$ ), revealing spectral blue-shifts with two time constants of $9 \pm 3$ ps and $20 \pm 2$ ps, respectively (see Figure 4c). This transient blue-shift is accompanied by a narrowing of the fluorescence bandwidths of the two peaks with time constants of $17 \pm 4$ ps and $10 \pm 1$ ps, respectively (see Figure $4 \mathrm{~d}$ ). The narrowing of the peaks explains the transient increase of the fluorescence in a time range from 10 to 30 ps (e.g., around $16,600 \mathrm{~cm}^{-1}$ ). We note that a transient blue-shift of the fluorescence has also been observed in other studies [48]. Several explanations have been given; the explanations that are assumed to be the most reliable are a coupling to the vibrational modes of the excited molecule or a direct interaction with solvent molecules. 


\subsection{Transient Absorption Measurements}

For a more detailed description of the underlying electronic dynamics, we performed transient absorption measurements using femtosecond time-resolved Vis-pump supercontinuum probe spectroscopy. Upon excitation at $400 \mathrm{~nm}$, we investigated the transient dynamics from 430 to $720 \mathrm{~nm}$ from femtoseconds up to $1.2 \mathrm{~ns}$. The absorbance changes are presented for the complete spectral range and for delay times up to $1.2 \mathrm{~ns}$ in a contour plot in Figure 5.

In the whole spectral range from 430 to $720 \mathrm{~nm}$, we observe positive signals upon excitation up to $1.2 \mathrm{~ns}$, except for the bleaching region from 560 to $580 \mathrm{~nm}$ and the stimulated emission region around $590 \mathrm{~nm}$ and at $650 \mathrm{~nm}$. In the sub-picosecond time range, a change in the positive signal at wavelengths between $430 \mathrm{~nm}$ and $550 \mathrm{~nm}$ and around $630 \mathrm{~nm}$ is visible. These changes are followed by an increase in the stimulated emission signal at $650 \mathrm{~nm}$, accompanied by the rise of stimulated emission at $596 \mathrm{~nm}$. On the same time scale, the positive signal around $450 \mathrm{~nm}$ decays slightly and the positive signal around $540 \mathrm{~nm}$ rises.

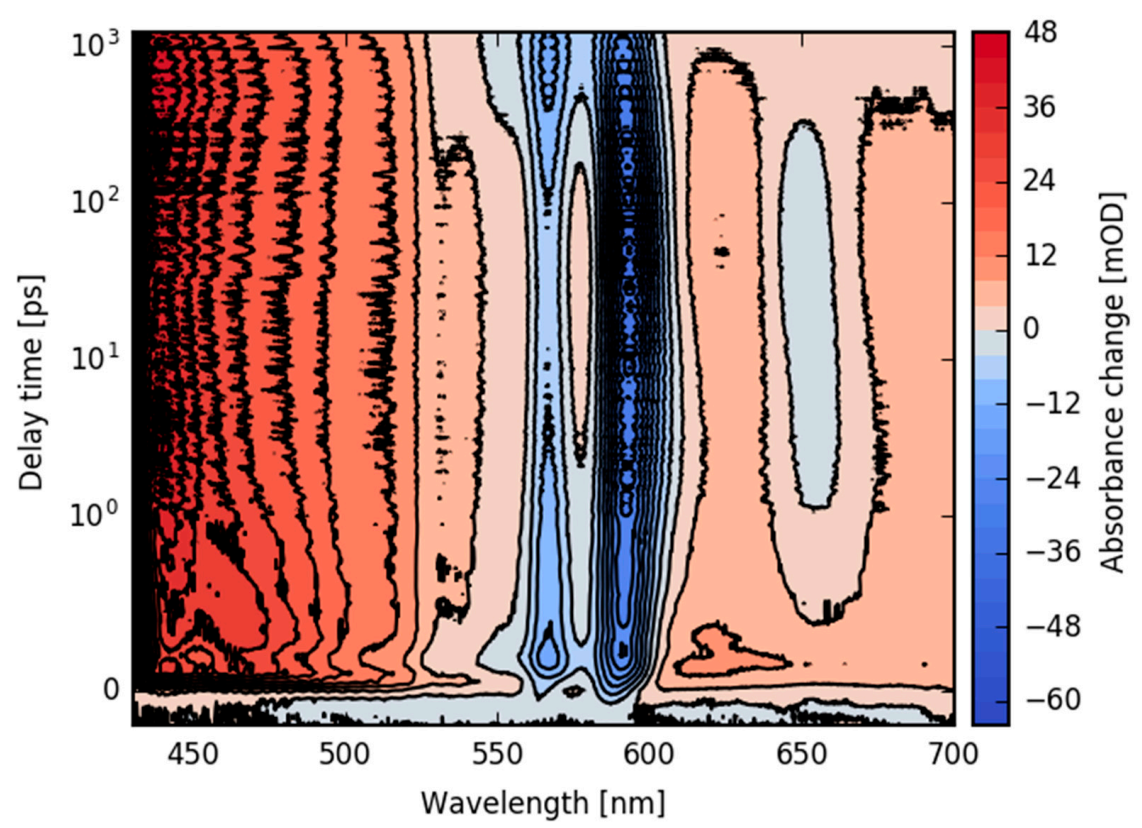

Figure 5. Contour plot of the absorption change upon excitation at $400 \mathrm{~nm}$ as a function of wavelength and of delay time from fs to $1.2 \mathrm{~ns}$. The change in absorption is color-coded.

Since the fluorescence of the $Q$ band ( $S_{1}$ state) exhibits specific peaks at $596 \mathrm{~nm}$ and $650 \mathrm{~nm}$ (see Figure 1), we assign the decreasing absorption at $596 \mathrm{~nm}$ and $650 \mathrm{~nm}$ to a rise of the stimulated emission (SE) of the $\mathrm{Q}$ band, demonstrating Soret band to $\mathrm{Q}$ band transition in agreement with our time-resolved fluorescence data. As a consequence, the change in the positive signals can be assigned to the decay of the SE and the excited state absorption (ESA) of the Soret band, and rise of the ESA of the $Q$ band. It was demonstrated that the $Q$ band of corroles consists of two singlet excited states $\left(\mathrm{S}_{1}\right.$ and $\left.\mathrm{S}_{2}\right)$ [44]. Our data presented here show dynamics that could be interpreted as a single $\mathrm{Q}$ band state. On a time scale of hundreds of picoseconds, the negative signal of the stimulated emission decays, accompanied by a decay of positive signals for long wavelengths. This results in an increase of the bleaching band. Since the stimulated emission signal decays to zero, the remaining positive and negative contributions are due to triplet absorption and bleaching signals.

In Figure 6, selected absorbance difference spectra are obtained for given delay times, taking cuts from Figure 5. Comparison of early delay times before Soret to $Q$ band transition (0.2 ps, blue line in Figure 6) with delay times of $Q$ band population ( 0.6 ps, and 100 ps, green and orange line in Figure 6, respectively) demonstrates the rise of the SE at around $650 \mathrm{~nm}$ and $596 \mathrm{~nm}$, as well as the rise of ESA 
around $550 \mathrm{~nm}$. The positive signal at around $680 \mathrm{~nm}$ decays with the rise of Q band ESA, indicating a stronger and broader positive band of Soret band ESA compared to Q band ESA. From the early absorbance difference spectra at $0.2 \mathrm{ps}$, when most of the population is in the Soret band and Q band $\mathrm{SE}$ is negligible, we can estimate the initial bleaching signal. The negative peak at $590 \mathrm{~nm}$ has a signal of $-24 \mathrm{mOD}$, masked by the positive Soret band ESA. By assuming a broad and flat Soret band ESA at $590 \mathrm{~nm}$ with a signal strength of $+8 \mathrm{mOD}$ (dashed horizontal line in Figure 6), we can estimate the initial bleaching signal to be $-32 \mathrm{mOD}$ (dashed vertical line in Figure 6).

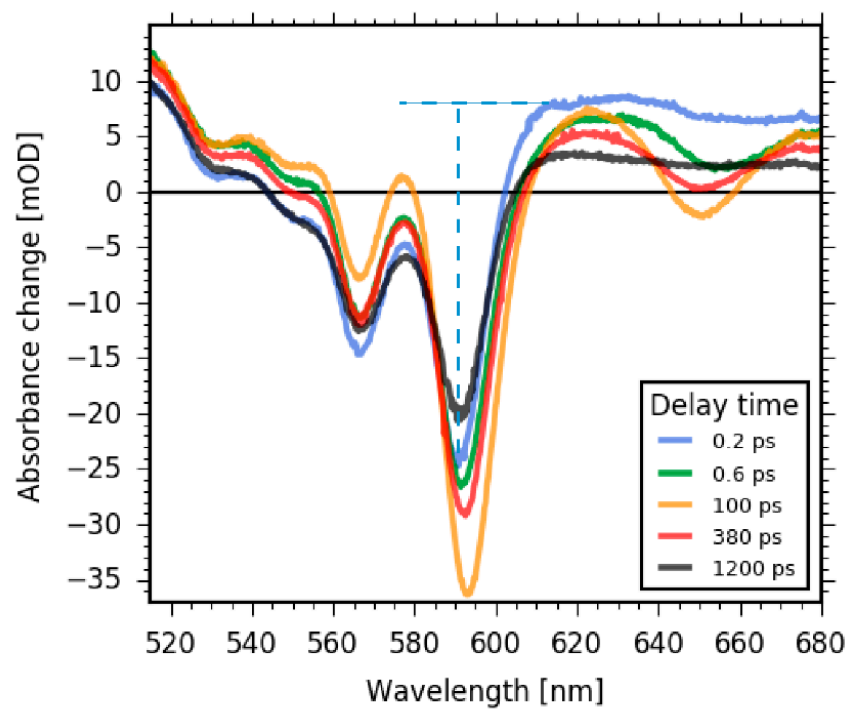

Figure 6. Selected absorbance difference spectra displaying the rise and decay of $Q$ band stimulated emission (SE) signals as well as the change in excited state absorption (ESA). Over short time scales, the formation of SE at $650 \mathrm{~nm}$ is clearly visible. Longer delay times show the decay of SE at $650 \mathrm{~nm}$ and the decay of ESA around $550 \mathrm{~nm}$. At early delay times ( $0.2 \mathrm{ps}$, blue line), the height of the Soret band ESA at $590 \mathrm{~nm}$ can be estimated by way of the blue dashed horizontal line and the signal strength of the initial bleaching signal at $590 \mathrm{~nm}$ by way of the blue dashed vertical line to be about $32 \mathrm{mOD}$.

Around $100 \mathrm{ps}$ after excitation, the positive signal at wavelengths between $520 \mathrm{~nm}$ and $685 \mathrm{~nm}$ due to the $Q$ band ESA starts to decrease, accompanied by a decrease in the negative SE signal at $596 \mathrm{~nm}$ and $650 \mathrm{~nm}$. These changes indicate a loss of SE and depopulation of the $S_{1}$ state. Since the bleaching signals at $565 \mathrm{~nm}$ and $590 \mathrm{~nm}$ do not recover (see Figure 6) and the SE contribution at $650 \mathrm{~nm}$ vanishes completely, we assign this process to intersystem crossing and triplet formation. Due to the decaying of overlapping bands, the bleaching signal becomes stronger with triplet formation. Thus, we can conclude that bleaching recovery on this time scale is small or negligible. Subsequently, we assign the remaining positive signal for delay times around $1 \mathrm{~ns}$ to triplet state absorption.

\subsection{Global Analysis}

The complete dataset is well represented by the absorbance difference spectra and the transients at given wavelengths shown in Figure 7a. The signal to noise ratio is very good and allows for a global analysis of the complete dataset with five exponential decay functions. From the global analysis, we received five decay associated spectra (DAS) and associated decay times $\tau_{1-5}$, as displayed in Figure $7 \mathrm{~b}$. 

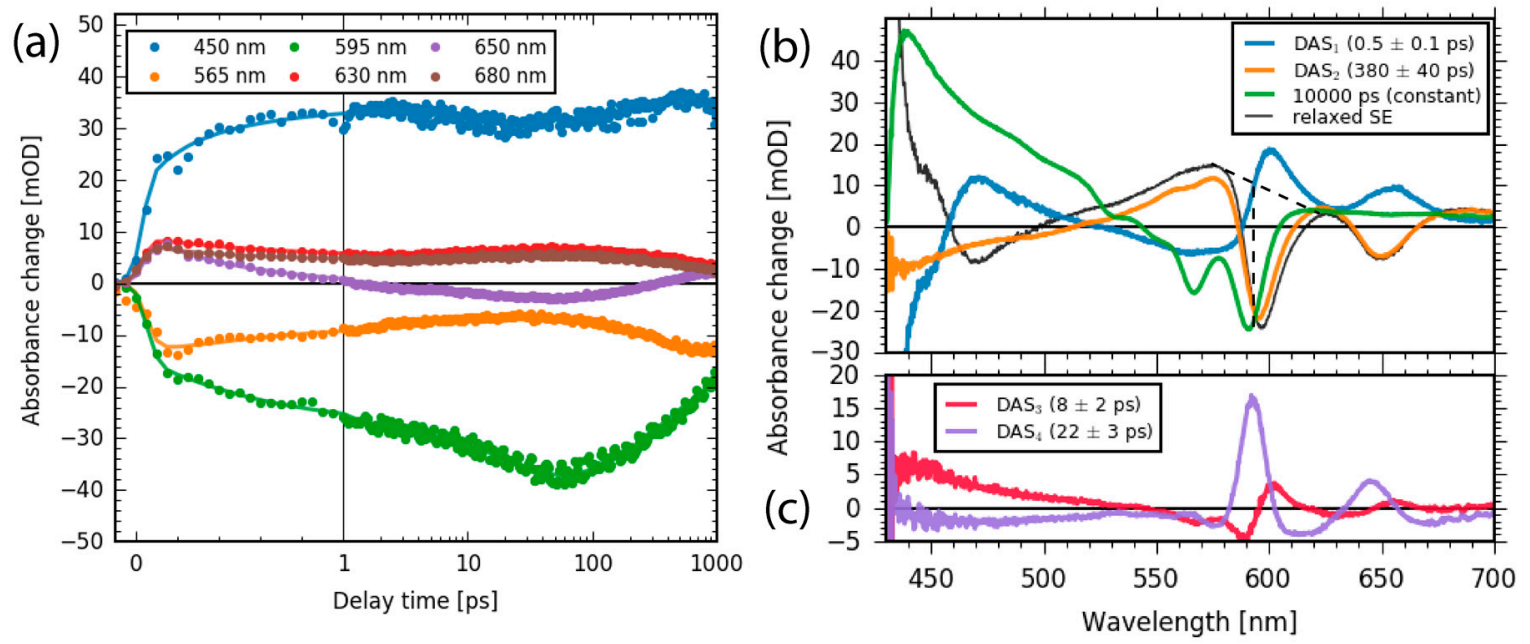

Figure 7. (a) Transient signals for selected wavelengths (dots) and fits (lines); (b) Decay associated spectra (DAS) describing the electronic dynamics of the Sb-corrole. DAS ${ }_{1}$ shows the Soret to Q band transition and rise of the $\mathrm{SE}$ of the $\mathrm{Q}$ band. $\mathrm{DAS}_{2}$ corresponds to triplet formation. The spectrum with a time constant of 10,000 ps represents the triplet decay and the decay of ground state bleach. The inverted sum of $\mathrm{DAS}_{1}, \mathrm{DAS}_{3}$, and $\mathrm{DAS}_{4}$ is presented as relaxed fluorescence (black line), with an added offset to match the signal of $\mathrm{DAS}_{2}$ at $700 \mathrm{~nm}$; (c) two additional DAS showing cooling processes associated with a spectral blue shift and a narrowing of the respective peaks.

The first DAS 1 spectrum (blue line in Figure $7 \mathrm{~b}$ ) with a time constant of $\tau_{1}=550 \pm 50 \mathrm{fs}$ can be assigned to Soret band to $\mathrm{Q}$ band transition. The two positive peaks at $600 \mathrm{~nm}$ and $655 \mathrm{~nm}$ imply a rise of a non-equilibrated SE of the $S_{1}$ state. The negative contribution at around $450 \mathrm{~nm}$ reflects the decay of the Soret band SE and the negative contribution at around $560 \mathrm{~nm}$ indicates the rise of the $\mathrm{Q}$ band ESA, while the positive contribution at around $480 \mathrm{~nm}$ can be assigned to the decay of Soret band ESA. The positive signals at $600 \mathrm{~nm}$ in DAS 1 (blue line in Figure 7b), DAS 4 (violet line in Figure 7c) and the dispersive feature in $\mathrm{DAS}_{3}$ (red line Figure 7c) reflect the rise and relaxation of the non-equilibrated SE. The relaxed SE is presented in Figure $7 \mathrm{~b}$ (black line) and exhibits the same signal strength in stimulated emission at $650 \mathrm{~nm}$ as $\mathrm{DAS}_{2}$. Hence, the fluorescence decay of the $\mathrm{Q}$ band is negligible on the time scale of our measurement and can be estimated to be smaller than $5 \%$. This is in agreement with a comparison between the fluorescence decay time of $0.38 \mathrm{~ns}$ for Sb-tpfc- $\mathrm{F}_{2}$ with $6.6 \mathrm{~ns}$ for Al-tpfc-py2 fluorescence, resulting in a fluorescence reduction of $5 \%$.

The signal strength of the relaxed SE can be estimated to be about $35 \mathrm{mOD}$ by the negative peak at $600 \mathrm{~nm}$ (black dotted line in Figure $7 \mathrm{~b}$ ). We estimated the initial bleach signal to be about $32 \mathrm{mOD}$ (see Figure 6), showing a similar signal strength to the relaxed fluorescence (with an error of $10 \%$ ). Thus, we see no indications of a loss in population by Soret band to $Q$ band transition. Since we do not see any contributions from the bleaching signal in the $\mathrm{DAS}_{1}$ spectrum, no bleaching recovery occurs on that time scale and therefore all population is transferred to the $Q$ band.

The second $\mathrm{DAS}_{2}$ describes dynamics with a time constant of $\tau_{2}=380 \pm 40 \mathrm{ps}$. The $\mathrm{DAS}_{2}$ shows two negative peaks at the spectral position of the fluorescence at $595 \mathrm{~nm}$ and $650 \mathrm{~nm}$, demonstrating the complete decay of the stimulated emission signal (also visible in Figures 5 and 6). Moreover, no signatures from the bleaching signal are visible in the $\mathrm{DAS}_{2}$ spectrum. Thus, a new electronic state is populated that shows no stimulated emission to the ground state. Therefore, we conclude that the triplet state is formed with a time constant of $\tau_{2}=380 \pm 40 \mathrm{ps}$.

Moreover, a broad negative signal at wavelengths from 430 to $520 \mathrm{~nm}$ and a broad positive signal between $515 \mathrm{~nm}$ and $580 \mathrm{~nm}$ is visible in the DAS 2 spectrum. The broad positive and negative contributions represent the decrease and increase of ESA from the singlet and triplet state, respectively. 
Since the SE signal completely vanishes and the bleaching did not recover over longer delay times, the quantum yield for $\mathrm{Q}$ band to triplet state on this time scale is about $100 \%$. This results in a total intersystem crossing (ISC) yield between $95 \%$ and $99 \%$ with a time constant of $380 \mathrm{ps}$. This is in agreement with data from Knyukshto et al. measuring ISC yields of $94 \%$ and $99 \%$ for time constants of $0.85 \mathrm{~ns}$, and $>0.1 \mathrm{~ns}$, respectively [49].

Since the $\mathrm{DAS}_{2}$ spectrum (Figure 8, pink line) only consists of two contributions, the bleaching signal (negative) and the triplet absorption (positive), we can calculate the pure triplet absorption spectrum by adding the linear absorption spectrum (negative in Figure 8, blue line) to the $\mathrm{DAS}_{2}$ spectrum and minimize the spectral contributions of the complex linear absorption spectrum in triplet absorption. As visible in Figure 8 (green line), some features of the linear absorption spectrum cannot be subtracted completely from the triplet absorption spectrum; this is probably due to small deviations in wavelength calibration. Nevertheless, the shape of the triplet absorption spectrum (Figure 8, green line) shows a peak at short wavelengths and a decaying broad and flat tail down to $700 \mathrm{~nm}$.

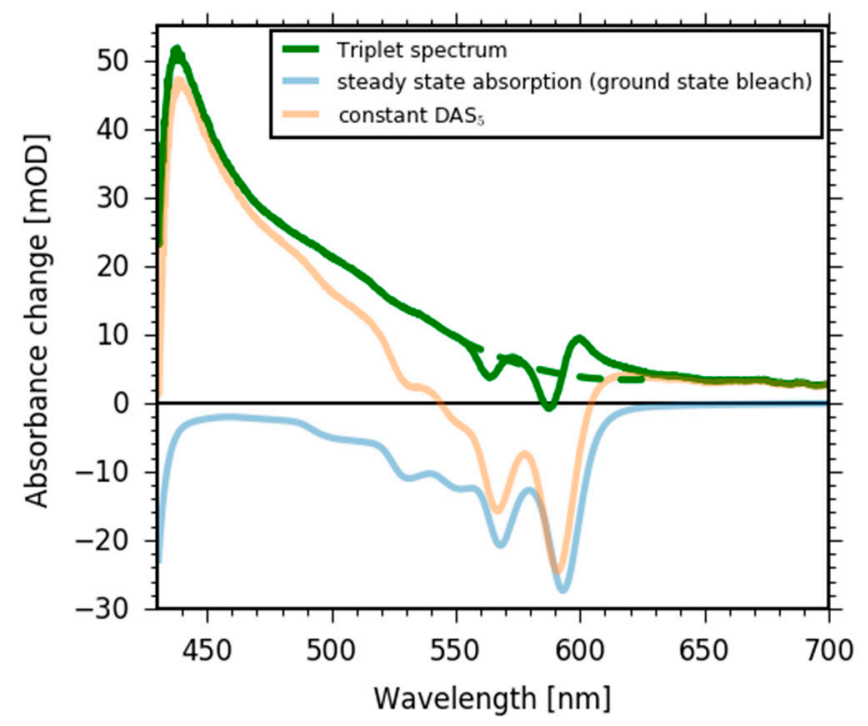

Figure 8. Triplet absorption spectrum (green line) calculated by subtracting the ground state bleach from the 10,000 ps DAS spectrum. The two dips and the following small positive peak are due to small calibration errors and resolution differences. The dashed line shows a possible correction of the spectrum.

Furthermore, comparison of the $\mathrm{DAS}_{1}$ and DAS 2 spectra displays a zero crossing at $520 \mathrm{~nm}$ for both spectra. If we assume that no triplet is generated upon Soret band to $\mathrm{Q}$ band transition, this indicates the same extinction coefficients at $520 \mathrm{~nm}$ for rising triplet absorption and decaying $Q$ band ESA absorption (in $\mathrm{DAS}_{2}$ ), as well as the same extinction coefficients at $520 \mathrm{~nm}$ for rising $\mathrm{Q}$ band ESA absorption and decaying Soret band ESA absorption (in DAS $_{1}$ ).

A closer investigation of the $Q$ band SE for delay times between 1 ps and 50 ps exhibits a shift to higher energies (see Figures 5 and 6). The two spectra, $\mathrm{DAS}_{3}$ and $\mathrm{DAS}_{4}$, show dispersive and negative-positive-negative features at around $590 \mathrm{~nm}$ and $650 \mathrm{~nm}$, with times constants of $\tau_{3}=8.1 \pm 2.0 \mathrm{ps}$ and $\tau_{4}=22 \pm 3$ ps. These features might reflect spectral shifts and a narrowing of bands at around $590 \mathrm{~nm}$ and $650 \mathrm{~nm}$, corroborating the fluorescence data in Figure 4c,d. The DAS 4 spectrum (Figure 7c, violet line) exhibits a prominent positive peak at $590 \mathrm{~nm}$, with a small negative region at $575 \mathrm{~nm}$. This can be interpreted as a blue-shift of the stimulated emission with a time constant of 22 ps. This is in perfect agreement with the fluorescence data presented in Figure 4c (orange line). Moreover, a broad positive signal at around $450 \mathrm{~nm}$ is visible in $\mathrm{DAS}_{3}$ and a broad negative signal at 
around $480 \mathrm{~nm}$ in DAS 4 . We assign these two features to spectral shifts in the Q band ESA, reflecting vibrational cooling accompanied with a narrowing and blue-shift of the $Q$ band SE [48].

\section{Discussion}

$\mathrm{Sb}$-tpfc- $\mathrm{F}_{2}$, among other corrole species, proves to have very promising photophysical properties, such as high triplet quantum yield, with possible applications in photodynamic therapy. In this study, we were able to trace electronic dynamics upon Soret band excitation of Sb-tpfc- $\mathrm{F}_{2}$ in real time. The use of two complementary methods lead to a consistent picture of the underlying photophysical dynamics. We were able to directly observe an internal conversion from the Soret band to $\mathrm{Q}$ band with a time constant of $0.5 \pm 0.1 \mathrm{ps}$. On a longer time scale, intersystem crossing took place, leading to triplet generation with a time constant of $380 \pm 40 \mathrm{ps}$ in the transient absorption measurements and a fluorescence decay of $450 \pm 40$ ps in the transient fluorescence experiments. Thus, triplet formation occured on a time scale of $400 \mathrm{ps}$. The triplet yield was determined from transient absorption measurement and amounts to a about 95 to $99 \%$. This indicates a significant spin-orbit coupling due to the antimony ion.

Relaxation processes were observed in both transient fluorescence and transient absorption measurements, displaying a blue-shift and a narrowing of the fluorescence spectra and Q band SE and ESA, respectively. These processes could be explained by the vibrational cooling of intramolecular modes via intramolecular energy relaxation or the cooling and rearrangement of solvent modes via intermolecular vibrational energy relaxation. Similar vibrational cooling time constants of about 2 ps and 20 ps were reported for heme systems upon photodissociation of carbon monoxide [50].

The resulting decay paths are depicted in Figure 9. However, further investigations on different corrole complexes are needed to fully understand the effect of different metal ions and ligands. This knowledge is crucial to further fine-tune the photophysics of corrole complexes in the future.

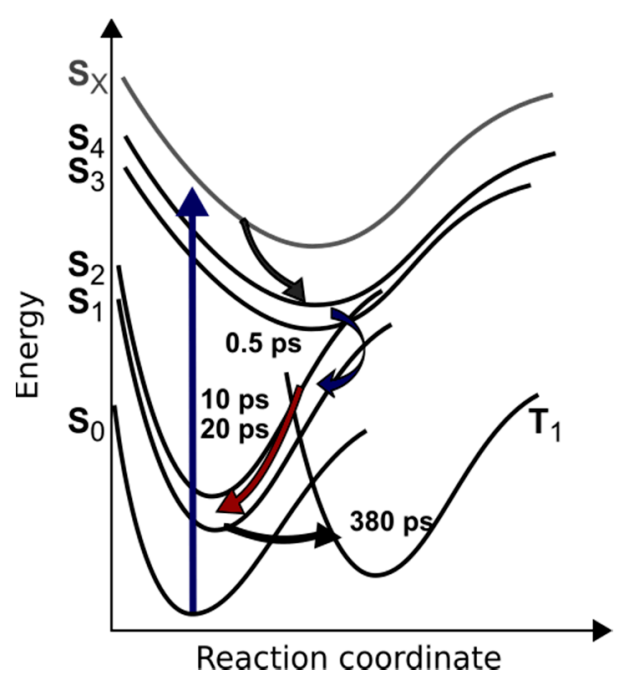

Figure 9. Photoreaction pathway of Sb-tpfc- $\mathrm{F}_{2}$ after excitation with a $400 \mathrm{~nm}$ pulse at the high energy side of the Soret band. Arrows indicate internal conversion from the Soret to $Q$ band on a short time scale of $0.5 \mathrm{ps}$, with subsequent cooling processes on time scales of $10 \mathrm{ps}$ and $20 \mathrm{ps}$. Intersystem crossing from the $S_{1}$ state to the $T_{1}$ state was observed with a time constant of $400 \mathrm{ps}$.

\section{Materials and Methods}

The transient absorption experiment was performed using a Ti:sapphire Laser Legend USP from Coherent (Santa Clara, CA, USA), with a center wavelength of $800 \mathrm{~nm}$ and a pulse duration of $80 \mathrm{fs}$. The repetition rate is $1088 \mathrm{~Hz}$ and the energy of the pulse is approx $2.6 \mathrm{~mJ}$. The setup consists of two parts, for pump and probe pulse generation. The pump pulse is generated by second harmonic 
generation in a $\mathrm{BBO}$ ( $\beta$-bariumborate) crystal, giving a pump pulse energy of $6 \mu \mathrm{J}$ attenuated to about $0.5 \mu \mathrm{J}$. The change in absorption between the pumped and unpumped sample was measured by using a mechanical chopper blocking every second pump pulse. A parallel $\left(\mathrm{A}_{\mathrm{pa}}\right)$ and perpendicular $\left(\mathrm{A}_{\mathrm{pe}}\right)$ signal was obtained by rotation of the pump pulse polarisation using a rotatable $\lambda / 2$ plate. Isotropic absorbance changes $\left(\mathrm{A}_{\text {iso }}\right)$ were calculated by $\mathrm{A}_{\text {iso }}=\left(\mathrm{A}_{\text {pa }}+2 \mathrm{~A}_{\mathrm{pe}}\right) / 3$.

The broad supercontinuum probe pulse was generated by focusing the fundamental in a $1 \mathrm{~cm}$ fused silica cuvette filled with water. The resulting supercontinuum pulse covered the whole visible spectrum from 390 up to $750 \mathrm{~nm}$. Due to saturation, we used an HR 800 mirror (Laseroptik, Garbsen, Germany) and an optical SCHOTT BG 26 filter (Schott AG, Mainz, Germany) to cut off wavelengths longer than $750 \mathrm{~nm}$. The probe pulse was delayed using a translation stage M535.22 from Physik Instrumente (Karlsruhe, Germany) with an accuracy of $0.1 \mu \mathrm{m}$.

After passing the sample, the probe beam was coupled in an optical spectrometer (Shamrock from Andor, Entwicklungsbüro Stresing, Berlin, Germany). The system response was better than $100 \mathrm{fs}$ (typically $\sim 80 \mathrm{fs}$ ) [51]. The generated probe pulse supercontinuum exhibited a strong chirp, resulting in a shift of time-zero as a function of the wavelength. The data were time-zero corrected by modeling the chirp with a third order polynomial [51].

Femtosecond fluorescence spectra were measured with a broadband up-conversion setup FLUPS (fluorescence up-conversion spectroscopy, LIOP-TEC, Radevormwald, Germany) [52-54]. The sample was excited with $400 \mathrm{~nm}$ pump pulses. Fluorescence was collected with an off-axis Schwarzschild mirror objective and re-focused onto a BBO crystal (100 $\mu \mathrm{m}$ thick, EKSMA Optics, Vilnius, Lithuania), where it was up-converted (type II) with $1340 \mathrm{~nm}$ gate pulses. A time resolution of $100 \mathrm{fs}$, as measured at full width at half maximum (FWHM) of solvent Raman signal, was achieved, despite the large interaction angle $\left(21^{\circ}\right)$, by tilting the gate pulse front [52]. For the measurements in this work, the crystal was set to case A conditions as described in Gerecke et al. [54]. Up-converted fluorescence was detected, simultaneously at all relevant wavelengths, by a spectrograph equipped with a CCD camera (Andor DU420 BU, Andor Technology Ltd., Belfast, UK). Transient spectra were collected in $20 \mathrm{fs}, 400 \mathrm{fs}$ and $10 \mathrm{ps}$ steps up to $500 \mathrm{ps}$, integration over $0.5 \mathrm{~s}$ was used at each step of a time scan and the results from four scans were averaged. Finally, corrections for the dispersion of group velocity and photometric response were applied.

Sb-tpfc- $F_{2}$ was prepared according to Luobeznova et al. [22]. The sample was dissolved in toluene.

Acknowledgments: We thank N.P. Ernsting for valuable discussions and the Deutsche Forschungsgemeinschaft (SFB-1078, projects B5 to K.H) for financial support.

Author Contributions: C.Z. performed the transient absorption measurements and analyzed the data, T.S. built the transient absorption set-up, programmed the Python analysis tools, and discussed the transient absorption and fluorescence results, M.G. performed the transient fluorescence measurements, A.B. planned the experiment, discussed results and measured triplet formation with transient EPR (data not shown), A.M. and Z.G. prepared the samples and discussed the results, K.H. planned the experiments, discussed the results, and wrote the manuscript.

Conflicts of Interest: The authors declare no conflict of interest.

\section{References}

1. Aviv, I.; Gross, Z. Corrole-based applications. Chem. Commun. 2007, 1987-1999. [CrossRef]

2. Santos, C.I.M.; Barata, J.F.B.; Calvete, M.J.F.; Vale, L.S.H.P.; Dini, D.; Meneghetti, M.; Neves, M.G.P.M.S.; Faustino, M.A.F.; Tome, A.C.; Cavaleiro, J.A.S. Synthesis and functionalization of corroles. An insight on their nonlinear optical absorption properties. Curr. Org. Synth. 2014, 11, 29-41. [CrossRef]

3. Voloshchuk, R.; Tasior, M.; Ciuciu, A.I.; Flamigni, L.; Gryko, D.T. Corrole-imide dyads—Synthesis and optical properties. J. Porphyr. Phthalocyanines 2015, 19, 479-491. [CrossRef]

4. Wang, L.L.; Wang, H.; Cheng, F.; Liang, Z.H.; Liu, C.F.; Li, Y.; Wang, W.Q.; Peng, S.H.; Wang, X.; Ying, X.; et al. Investigation of excited-state photophysical properties of water soluble gallium corrole. J. Phys. Chem. C 2017, 121, 12350-12357. [CrossRef]

5. Vestfrid, J.; Botoshansky, M.; Palmer, J.H.; Durrell, A.C.; Gray, H.B.; Gross, Z. Iodinated aluminum(III) corroles with long-lived triplet excited states. J. Am. Chem. Soc. 2011, 133, 12899-12901. [CrossRef] [PubMed] 
6. Wagnert, L.; Berg, A.; Stavitski, E.; Berthold, T.; Kothe, G.; Goldberg, I.; Mahammed, A.; Simkhovich, L.; Gross, Z.; Levanon, H. Exploring the photoexcited triplet states of aluminum and tin corroles by time-resolved Q-band epr. Appl. Magn. Reson. 2006, 30, 591-604. [CrossRef]

7. Wagnert, L.; Rubin, R.; Berg, A.; Mahammed, A.; Gross, Z.; Levanon, H. Photoexcited triplet state properties of brominated and nonbrominated $\mathrm{Ga}(\mathrm{III})$-corroles as studied by time-resolved electron paramagnetic resonance. J. Phys. Chem. B 2010, 114, 14303-14308. [CrossRef] [PubMed]

8. Lemon, C.M.; Halbach, R.L.; Huynh, M.; Nocera, D.G. Photophysical properties of $\beta$-substituted free-base corroles. Inorg. Chem. 2015, 54, 2713-2725. [CrossRef] [PubMed]

9. Brennan, B.J.; Lam, Y.C.; Kim, P.M.; Zhang, X.; Brudvig, G.W. Photoelectrochemical cells utilizing tunable corroles. ACS Appl. Mater. Interfaces 2015, 7, 16124-16130. [CrossRef] [PubMed]

10. Ghosh, A. Electronic structure of corrole derivatives: Insights from molecular structures, spectroscopy, electrochemistry, and quantum chemical calculations. Chem. Rev. 2017, 117, 3798-3881. [CrossRef] [PubMed]

11. Aviv-Harel, I.; Gross, Z. Coordination chemistry of corroles with focus on main group elements. Coord. Chem. Rev. 2011, 255, 717-736. [CrossRef]

12. Palmer, J. Transition metal corrole coordination chemistry. In Molecular Electronic Structures of Transition Metal Complexes; Mingos, D.M.P., Day, P., Dahl, J.P., Eds.; Springer: Berlin/Heidelberg, Germany, 2012; Volume 142, pp. 49-89.

13. Walker, D.; Chappel, S.; Mahammed, A.; Brunschwig, B.S.; Winkler, J.R.; Gray, H.B.; Zaban, A.; Gross, Z. Corrole-sensitized $\mathrm{TiO}_{2}$ solar cells. J. Porphyr. Phthalocyanines 2006, 10, 1259-1262. [CrossRef]

14. Hwang, J.Y.; Lubow, D.J.; Sims, J.D.; Gray, H.B.; Mahammed, A.; Gross, Z.; Medina-Kauwe, L.K.; Farkas, D.L. Investigating photoexcitation-induced mitochondrial damage by chemotherapeutic corroles using multimode optical imaging. J. Biomed. Opt. 2012, 17, 015003. [CrossRef] [PubMed]

15. Barata, J.F.B.; Zamarrón, A.; Neves, M.G.P.M.S.; Faustino, M.A.F.; Tomé, A.C.; Cavaleiro, J.A.S.; Röder, B.; Juarranz, Á.; Sanz-Rodríguez, F. Photodynamic effects induced by meso-tris(pentafluorophenyl)corrole and its cyclodextrin conjugates on cytoskeletal components of HeLa cells. Eur. J. Med. Chem. 2015, 92, 135-144. [CrossRef] [PubMed]

16. Hwang, J.Y.; Lubow, D.J.; Chu, D.; Sims, J.; Alonso-Valenteen, F.; Gray, H.B.; Gross, Z.; Farkas, D.L.; Medina-Kauwe, L.K. Photoexcitation of tumor-targeted corroles induces singlet oxygen-mediated augmentation of cytotoxicity. J. Control. Release 2012, 163, 368-373. [CrossRef] [PubMed]

17. Agadjanian, H.; Ma, J.; Rentsendorj, A.; Valluripalli, V.; Hwang, J.Y.; Mahammed, A.; Farkas, D.L.; Gray, H.B.; Gross, Z.; Medina-Kauwe, L.K. Tumor detection and elimination by a targeted gallium corrole. Proc. Natl. Acad. Sci. USA 2009, 106, 6105-6110. [CrossRef] [PubMed]

18. Preuss, A.; Saltsman, I.; Mahammed, A.; Pfitzner, M.; Goldberg, I.; Gross, Z.; Roder, B. Photodynamic inactivation of mold fungi spores by newly developed charged corroles. J. Photochem. Photobiol. B 2014, 133, 39-46. [CrossRef] [PubMed]

19. Pohl, J.; Saltsman, I.; Mahammed, A.; Gross, Z.; Roder, B. Inhibition of green algae growth by corrole-based photosensitizers. J. Appl. Microbiol. 2015, 118, 305-312. [CrossRef] [PubMed]

20. Barata, J.F.B.; Pinto, R.J.B.; Serra, V.I.R.C.V.; Silvestre, A.J.D.; Trindade, T.; Neves, M.G.P.M.S.; Cavaleiro, J.A.S.; Daina, S.; Sadocco, P.; Freire, C.S.R. Fluorescent Bioactive Corrole Grafted-Chitosan Films. Biomacromolecules 2016, 17, 1395-1403. [CrossRef] [PubMed]

21. Hwang, J.Y.; Wachsmann-Hogiu, S.; Ramanujan, V.K.; Ljubimova, J.; Gross, Z.; Gray, H.B.; Medina-Kauwe, L.K.; Farkas, D.L. A multimode optical imaging system for preclinical applications in vivo: Technology development, multiscale imaging, and chemotherapy assessment. Mol. Imaging Biol. 2012, 14, 431-442. [CrossRef] [PubMed]

22. Luobeznova, I.; Raizman, M.; Goldberg, I.; Gross, Z. Synthesis and full characterization of molybdenum and antimony corroles and utilization of the latter complexes as very efficient catalysts for highly selective aerobic oxygenation reactions. Inorg. Chem. 2006, 45, 386-394. [CrossRef] [PubMed]

23. Barata, J.F.B.; Daniel-da-Silva, A.L.; Neves, M.G.P.M.S.; Cavaleiro, J.A.S.; Trindade, T. Corrole-silica hybrid particles: Synthesis and effects on singlet oxygen generation. RSC Adv. 2013, 3, 274-280. [CrossRef]

24. Reith, L.M.; Himmelsbach, M.; Schoefberger, W.; Knör, G. Electronic spectra and photochemical reactivity of bismuth corrole complexes. J. Photochem. Photobiol. A Chem. 2011, 218, 247-253. [CrossRef]

25. Flamigni, L.; Gryko, D.T. Photoactive corrole-based arrays. Chem. Soc. Rev. 2009, 38, 1635-1646. [CrossRef] [PubMed] 
26. Giribabu, L.; Kandhadi, J.; Kanaparthi, R.K. Phosphorus(V)corrole-porphyrin based hetero trimers: Synthesis, spectroscopy and photochemistry. J. Fluoresc. 2014, 24, 569-577. [CrossRef] [PubMed]

27. Giribabu, L.; Kandhadi, J.; Kanaparthi, R.K.; Reeta, P.S. Excitational energy and photoinduced electron transfer reactions in Ge(IV) corrole-porphyrin hetero dimers. J. Lumin. 2014, 145, 357-363. [CrossRef]

28. Shi, L.; Liu, H.-Y.; Shen, H.; Hu, J.; Zhang, G.-L.; Wang, H.; Ji, L.-N.; Chang, C.-K.; Jiang, H.-F. Fluorescence properties of halogenated mono-hydroxyl corroles: The heavy-atom effects. J. Porphyr. Phthalocyanines 2009, 13, 1221-1226. [CrossRef]

29. Vestfrid, J.; Goldberg, I.; Gross, Z. Tuning the photophysical and redox properties of metallocorroles by iodination. Inorg. Chem. 2014, 53, 10536-10542. [CrossRef] [PubMed]

30. Rabinovich, E.; Goldberg, I.; Gross, Z. Gold(I) and gold(III) corroles. Chem. Eur. J. 2011, 17, $12294-12301$. [CrossRef] [PubMed]

31. Palmer, J.H.; Day, M.W.; Wilson, A.D.; Henling, L.M.; Gross, Z.; Gray, H.B. Iridium corroles. J. Am. Chem. Soc. 2008, 130, 7786-7787. [CrossRef] [PubMed]

32. Palmer, J.H.; Durrell, A.C.; Gross, Z.; Winkler, J.R.; Gray, H.B. Near-IR phosphorescence of iridium(III) corroles at ambient temperature. J. Am. Chem. Soc. 2010, 132, 9230-9231. [CrossRef] [PubMed]

33. Shao, W.; Wang, H.; He, S.; Shi, L.; Peng, K.; Lin, Y.; Zhang, L.; Ji, L.; Liu, H. Photophysical properties and singlet oxygen generation of three sets of halogenated corroles. J. Phys. Chem. B 2012, 116, 14228-14234. [CrossRef] [PubMed]

34. Mahammed, A.; Tumanskii, B.; Gross, Z. Effect of bromination on the electrochemistry, frontier orbitals, and spectroscopy of metallocorroles. J. Porphyr. Phthalocyanines 2011, 15, 1275-1286. [CrossRef]

35. Zhang, L.; Liu, Z.-Y.; Zhan, X.; Wang, L.-L.; Wang, H.; Liu, H.-Y. Photophysical properties of electron-deficient free-base corroles bearing meso-fluorophenyl substituents. Photochem. Photobiol. Sci. 2015, 14, 953-962. [CrossRef] [PubMed]

36. Kowalska, D.; Liu, X.; Tripathy, U.; Mahammed, A.; Gross, Z.; Hirayama, S.; Steer, R.P. Ground- and excited-state dynamics of aluminum and gallium corroles. Inorg. Chem. 2009, 48, 2670-2676. [CrossRef] [PubMed]

37. Liu, X.; Mahammed, A.; Tripathy, U.; Gross, Z.; Steer, R.P. Photophysics of Soret-excited tetrapyrroles in solution. III. Porphyrin analogues: Aluminum and gallium corroles. Chem. Phys. Lett. 2008, 459, 113-118. [CrossRef]

38. Mahammed, A.; Gross, Z. Metallocorroles as photocatalysts for driving endergonic reactions, exemplified by bromide to bromine conversion. Angew. Chem. Int. Ed. 2015, 54, 12370-12373. [CrossRef] [PubMed]

39. Stensitzki, T.; Yang, Y.; Berg, A.; Mahammed, A.; Gross, Z.; Heyne, K. Ultrafast electronic and vibrational dynamics in brominated aluminum corroles: Energy relaxation and triplet formation. Struct. Dyn. 2016, 3, 043210. [CrossRef] [PubMed]

40. Steene, E.; Wondimagegn, T.; Ghosh, A. Resonance raman spectroscopy and density functional theoretical calculations of manganese corroles. A parallelism between high-valent metallocorroles and metalloporphyrins, relevant to horseradish peroxidase and chloroperoxidase compound I and II intermediates. J. Inorg. Biochem. 2002, 88, 113-118. [PubMed]

41. Mody, V.V.; Fitzpatrick, M.B.; Zabaneh, S.S.; Czernuszewicz, R.S.; Gałęzowski, M.; Gryko, D.T. Solvent effects on the electronic and vibrational properties of high-valent oxomolybdenum(V) 5,10,15-triphenylcorrole probed by UV-visible and resonance raman spectroscopy. J. Porphyr. Phthalocyanines 2009, 13, 1040-1052. [CrossRef]

42. Halvorsen, I.; Steene, E.; Ghosh, A. Resonance Raman marker bands of $\beta$-octahalogeno-mesotetraarylmetalloporphyrins. J. Porphyr. Phthalocyanines 2001, 5, 721-730. [CrossRef]

43. Wasbotten, I.H.; Wondimagegn, T.; Ghosh, A. Electronic absorption, resonance raman, and electrochemical studies of planar and saddled copper(III) meso-triarylcorroles. Highly substituent-sensitive Soret bands as a distinctive feature of high-valent transition metal corroles. J. Am. Chem. Soc. 2002, 124, 8104-8116. [CrossRef] [PubMed]

44. Yang, Y.; Jones, D.; von Haimberger, T.; Linke, M.; Wagnert, L.; Berg, A.; Levanon, H.; Zacarias, A.; Mahammed, A.; Gross, Z.; et al. Assignment of aluminum corroles absorption bands to electronic transitions by femtosecond polarization resolved Vis-pump IR-probe spectroscopy. J. Phys. Chem. A 2012, 116, 1023-1029. [CrossRef] [PubMed] 
45. Raavi, S.S.K.; Yin, J.; Grancini, G.; Soci, C.; Soma, V.R.; Lanzani, G.; Giribabu, L. Femtosecond to microsecond dynamics of Soret-band excited corroles. J. Phys. Chem. C 2015, 119, 28691-28700. [CrossRef]

46. Nastasi, F.; Campagna, S.; Ngo, T.H.; Dehaen, W.; Maes, W.; Kruk, M. Luminescence of mesopyrimidinylcorroles: Relationship with substitution pattern and heavy atom effects. Photochem. Photobiol. Sci. 2011, 10, 143-150. [CrossRef] [PubMed]

47. Wagnert, L.; Berg, A.; Stavitski, E.; Luobeznova, I.; Gross, Z.; Levanon, H. Structure-function relationship in antimony corrole photosensitizers. Time-resolved electron paramagnetic resonance and optical study. J. Porphyr. Phthalocyanines 2007, 11, 645-651. [CrossRef]

48. Sajadi, M.; Quick, M.; Ernsting, N.P. Femtosecond broadband fluorescence spectroscopy by down- and up-conversion in $\beta$-barium borate crystals. Appl. Phys. Lett. 2013, 103, 173514. [CrossRef]

49. Knyukshto, V.N.; Ngo, T.H.; Dehaen, W.; Maes, W.; Kruk, M.M. Phosphorescence of free base corroles. RSC Adv. 2016, 6, 43911-43915. [CrossRef]

50. Mizutani, Y.; Kitagawa, T. Direct observation of cooling of heme upon photodissociation of carbonmonoxy myoglobin. Science 1997, 278, 443-446. [CrossRef] [PubMed]

51. Stensitzki, T.; Muders, V.; Schlesinger, R.; Heberle, J.; Heyne, K. The primary photoreaction of channelrhodopsin-1: Wavelength dependent photoreactions induced by ground-state heterogeneity. Front. Mol. Biosci. 2015, 2, 41-51. [CrossRef] [PubMed]

52. Zhao, L.J.; Lustres, J.L.P.; Farztdinov, V.; Ernsting, N.P. Femtosecond fluorescence spectroscopy by upconversion with tilted gate pulses. Phys. Chem. Chem. Phys. 2005, 7, 1716-1725. [CrossRef] [PubMed]

53. Zhang, X.X.; Wurth, C.; Zhao, L.; Resch-Genger, U.; Ernsting, N.P.; Sajadi, M. Femtosecond broadband fluorescence upconversion spectroscopy: Improved setup and photometric correction. Rev. Sci. Instrum. 2011, 82, 063108. [CrossRef] [PubMed]

54. Gerecke, M.; Bierhance, G.; Gutmann, M.; Ernsting, N.P.; Rosspeintner, A. Femtosecond broadband fluorescence upconversion spectroscopy: Spectral coverage versus efficiency. Rev. Sci. Instrum. 2016, 87, 053115. [CrossRef] [PubMed]

Sample Availability: Samples of the compound Sb-tpfc- $\mathrm{F}_{2}$ are available from Zeev Gross and Atif Mahammed.

(c) 2017 by the authors. Licensee MDPI, Basel, Switzerland. This article is an open access article distributed under the terms and conditions of the Creative Commons Attribution (CC BY) license (http://creativecommons.org/licenses/by/4.0/). 